\title{
Utilising Peer Coaching as a Tool to Improve Student-Teacher Confidence and Support the Development of Classroom Practice
}

\author{
Tiffany Prince, Emma Snowden, Brian Matthews \\ Goldsmiths, University of London ${ }^{1}$, Engaging Education Consultancy ${ }^{2}$
}

\begin{abstract}
Teaching is a profession that requires a variety of skills and attributes that can be used to improve classroom practice. This research used peer coaching to help support the development of skills through dialogue and discussion. The research group were PGCE Science Students training to become teachers in the UK. They were introduced to peer coaching during the course. This article describes the structures developed to enable students to coach each other and thus enhance their development. The students were given questionnaires to ascertain to what extent they felt they had developed their skills as a result of being involved in peer coaching. The questionnaire design provided both qualitative and quantitative data. The evidence indicates that the peer coaching procedures had a positive impact on student teachers' professional development partially because it helped develop their confidence as a classroom practitioner and also because it equipped them with strategies to support them during their school practice. Data was analysed and has been used to draw conclusions to inform peer coaching in an education setting.
\end{abstract}

\section{Introduction}

The complexities involved in creating a purposeful classroom climate present student teachers with a range of professional, intellectual and emotional challenges. There are a variety of ways that students can be supported through their Initial Teacher Education [ITE], one of which is mentoring. In the UK this is usually provided by both a college-based and a schoolbased mentor. However, there is considerable evidence that peer coaching is useful for established teachers professional development $[1,2]$ and the authors felt that this should also be the case for students just embarking on their career where the demand to develop skills quickly are considerable. This article will focus on how peer coaching can be used to develop such skills including building relationships to improve performance in the classroom.

There has been a significant shift in teacher learning towards a more reflective and collaborative approach to developing teachers' classroom practice. In the 1980s, Showers and Joyce [3] showed that teachers who were involved in coaching sessions, whether as experts or participants, were much more likely to implement ideas into their classroom practice than those who did not participate in peer coaching. Hence, we can surmise that from an educational perspective, the better the skills of the teachers the more effective the learning in the classroom. The coaching relationship is about sharing classroom practice e.g. planning together, pooling experiences. Bakers and Showers [1] found that teachers who did this were much more likely to apply new approaches to their practice. Student teachers are often very tired and stressed when on school teaching practice. It was felt that by introducing the peer coaching methodology we would be enhancing student teachers' work through giving them opportunity to develop skills which will in turn help them to improve their classroom practice. Coaching increases the probability that teachers will try to implement ideas in the classroom.

It is widely recognised that PGCE courses and teaching in general have the potential to be stressful [4]. With this in mind peer coaching was put in place to provide an extra level of support for student teachers. Foltos [5] suggests "research shows that peer coaching methodology meets teachers' needs and is effective at shaping classroom practice" (p1). Russo [2] states that an important characteristic of professional development for teachers is that it must be ongoing and deeply embedded in teachers' practice. An underpinning rationale in our peer coaching methodology was to provide student teachers with opportunity for regular discussion and reflection about their practice to promote autonomous learning.

\section{Theoretical background}

There are various forms of coaching and mentoring. Both coaching and mentoring try to foster relationships that promote positive learning experiences for all involved. Darling et al [6] state that "mentoring relationships are shaped by the unique qualities each partner contributes to the dyad" (p765). We would argue that the same principles could be applied to the coaching processes. 
Coaching and mentoring practices are widely used in a variety of professions including both healthcare and education. There have been many studies looking at the effectiveness of coaching and mentoring [7-9] which have in general found both processes to be valuable. In some cases, such as those highlighted by Sue-Chan and Latham [10], mentoring was found to be the most effective. In University-based PGCE courses mentoring is well established and so an area that can be explored to enable students to develop is the area of coaching, and in particular, peer coaching $[3,11,12]$.

New priorities in education have seen an emphasis on the development of coaching and mentoring skills for teachers. In 2001 [13, 14] the National Strategy for Continuing Professional Development [CPD] strongly advocated the use of coaching and mentoring in teacher's continuing professional development. It was seen as important in raising standards and attainment in schools. The main focus of these programs was with experienced teachers, for example, the leading from the middle program for Teaching and Learning Leaders [15-17]. Through this research it has been found that there are certain key elements to promoting the effectiveness of the process. For example, Cordingly [16, 18] found that peer coaching was more effective when it was collaborative. Similarly, the National College for School Leadership [19] argue that:

Coaching is grounded in five key skills:

- establishing rapport and trust

- listening for meaning

- questioning for understanding

- prompting action, reflection and learning

- developing confidence and celebrating success (p14)

Developing confidence and celebrating success were key skills we wanted to focus on as studentteachers encounter much criticism and it is important they are able to recognise when things go well. Confidence is defined in overlapping ways. For example, Craig [20] argues that it is about being certain of ones abilities, having trust in people and a positive belief in the future. She sees confidence as a multidimensional concept related to self-esteem, self-efficacy and optimism, although she warns of the dangers of self-esteem. White [21] similarly sees confidence as having the following attributes: belief in positive achievements; persistence and self-awareness. In general confidence is seen at least as being able to make judgements on how well, or whether, we can do something [22]. Confidence is important for teachers, it is one of the key factors that matter in the classroom, and affects how pupils react to the instructions and communications teachers give.
Hollenbeck and Hall [22] believe that confidence is directly related to performance as confidence increases motivation, perceptions and thought processes. Craig [20] defines confidence as selfefficacy plus optimism and argues that those who are confident will find it easier to:

- $\quad$ Try new things and be more open to learning

- $\quad$ relish challenging tasks

- $\quad$ risk making mistakes

- $\quad$ express themselves as individuals

- $\quad$ say they don't understand and ask for help

- $\quad$ concentrate and not be sucked in by fear of failure. [20:5]

We would argue that all of the above are very important for trainee teachers and will help them become reflective practitioners and so develop their skills. There are few articles that have studied confidence and peer coaching or mentoring. Some are from a healthcare perspective where, for example, Loke and Chow [23] argue that peer coaching can have the effect of improving selfconfidence. Other articles refer to related subjects, for example, Malm [24] argues for the importance of personal dispositions for teachers, including self-awareness and empathy, while Kleitman and Stankov [25] have shown that self-confidence is related to the accuracy of performance and metacognitive awareness.

Creasy and Paterson [19] refer to the work of Whitmore [26] who sees coaching as helping people bring out the best in themselves and their teams, this links to ideas on emotional intelligence. Matthews [27] argues that 'emotional intelligence' is defined to be comparatively individualistic while 'emotional literacy' is a fluid concept with its roots in equity. Hence the term 'emotional literacy' is closer to the requirements of developing a teacher's professional attributes. The link between professional attributes and emotional literacy is clear, one of the key features of peer coaching is that the people involved have an opportunity to engage in a genuine dialogue. This involves the ability to listen with empathy, look for common ground, probe ideas with compassion, be open to new ideas, identify challenges and to act as a critical friend [3, 11, 12, 17, 19, 28]. However, this must occur irrespective of the sex, cultural background or social class of the participants, and so equity is a key feature of the emotional literacy component of peer coaching [27, 29]

Other writers pinpoint the features of peercoaching that reflects the importance of developing relationships. The GTC [11] draws attention to the importance of trust and support, enabling self-evaluation and development through 
focusing on key moments and developing new teaching strategies. They also mention the importance of confidentiality, dialogue and the use of questioning to probe and act as a stimulus for thinking and reflection.

We produced guidelines [30] for student teachers to use to establish a working framework and build a relationship with their peer coach. Our key points were that peer coaching requires:

1. Mutual agreement

2. A commitment to dialogue

3. That self-reflection would be encouraged

4. Awareness of the peer's potential

5. Sensitive questioning

6. Awareness and empathy

7. Positive listening

8. Celebration of successes.

We felt these were the conditions under which confidence in ones self can be developed. Greater awareness of self will promote emotional literacy and thus contribute to the progression of students through the course. Much of the literature on peercoaching/co-coaching make similar emphases but there is a lack of exploration of just how the key features of collaboration /cooperation and confidence can be developed.

\section{Methodology}

This study was designed to determine the effectiveness of peer coaching in supporting the development of professional attributes. Questionnaires were used to see if student teachers would respond positively to the process of coaching.

\subsection{The participants}

The participants were 38 students on a science PGCE course with an age range of 21 to 42 years. Of the 38 students, 22 were female and 16 were male.

\subsection{The procedure}

Students have a mentor in school and a college tutor to support them through their teaching practice. However, the purpose of the peer coach was to encourage student teachers to enter into constructive dialogues with their peers that would be supportive and open. Peers self-selected their pairs at the beginning of the course. Coaching guidelines were shared with students and explained alongside a rationale of being involved in a peer coaching project. Literature supports the notion that it is important for students to understand the processes through which the coaching will work in order for it to be successful
[6]. At this point it was decided that students would keep the same peer coach throughout the year to enable this relationship to develop. An important part of peer coaching is that it is an ongoing process.

The students had the opportunity to work together with their peer coaches during 8 college sessions. These usually involved some discussion guidelines to aid their conversations and help them to progress their learning. This enabled them to build a relationship with their peer coach before starting their school placements. They were also encouraged to meet during their self-study days and outside of college, which many of them did.

One of the key discussion points of these meetings was their school practice and how they evidence their progress on course. This was crucial as one of the worries student teachers have is about all the paperwork they must submit to pass the course. The opportunity to see what others on course were doing and discuss any concerns was an important step in building their confidence.

\subsection{The Questionnaires}

Students were given one interim questionnaire after their first term and two questionnaires at the end of their PGCE course. Questionnaires were chosen as the research tool as they enabled us to analyse responses from all the participants in the study and obtain an overall picture of the process. All three questionnaires consisted of short-answer and open-ended questions to encourage a range of responses. Opinion statements with a Likert scale response with bipolar adjectives on an 8 point scale were also used. The open-ended questions were framed to elicit data on such things as professional attributes while the Likert type questions would provide quantitative data. The first questionnaire was designed to gain interim data on how the peer coaches had established their relationships. The final two questionnaires were designed to yield a more qualitative response with open-ended questions about the process of both being coached and coaching.

\subsection{Data Analysis}

All three questionnaires gave a clear indication that the students knew what they had to do and revealed that the student teachers had built up a good relationship with their peer, based on mutual agreement. Questionnaire 1 (autumn term) asked i) if they 'completely understood the document on peer coaching'. This scored a mean of 7.0 out of 8 on the Likert scale. They were also asked if 'the document was very useful'. This scored 6.4 out of 8 on the Likert scale. When asked how good their relationship with the peer coach was they responded by answering as follows: 
Table 1. Relationship with peer coach (end of autumn term)

\begin{tabular}{|l|l|}
\hline & $\begin{array}{l}\text { Mean score } \\
\text { out of 8 }\end{array}$ \\
\hline $\begin{array}{l}\text { Relationship with peer coach } \\
\text { was very good }\end{array}$ & 7.29 \\
\hline $\begin{array}{l}\text { Usefulness of peer coach in } \\
\text { developing written tasks }\end{array}$ & 6.32 \\
\hline $\begin{array}{l}\text { Usefulness of peer coach in } \\
\text { developing teaching }\end{array}$ & 6.94 \\
\hline
\end{tabular}

During this period there was one peer coach who had been chosen by mutual agreement. By the end of the course many students had changed their peer coach, to someone who was in the same school or with whom it was easier to maintain a dialogue. At the end of the year a third questionnaire asked about the relationship with these peer coaches.

Table 2. Relationship with peer coach (end of summer term)

\begin{tabular}{|l|l|}
\hline & $\begin{array}{l}\text { Mean score } \\
\text { out of 8 }\end{array}$ \\
\hline $\begin{array}{l}\text { Relationship with the peer } \\
\text { coach was very good Q1 }\end{array}$ & 7.66 \\
\hline $\begin{array}{l}\text { The dialogue with my coach } \\
\text { was very useful Q3 }\end{array}$ & 7.27 \\
\hline
\end{tabular}

The results show a high degree of satisfaction with the peer coach. It increased slightly by the end of the course (Tables $1 \& 2$ ). This could be attributed to a longer period of peer coaching, where students were developing coaching skills as well as their understanding of what it is like to be a teacher. The aim of this intervention was to develop student teachers' confidence and thus practice in the classroom. Therefore as student teachers progress through the course we hope they will be able to communicate their ideas more clearly. Communication is vital for this process to be successful and opportunity for dialogue was a key theme to emerge from the second questionnaire. This is an interesting point to note as a small number of the coaches chose a peer to work with from a different course, or sometimes, even college or University. Where these peer coaches were more informal and had not gone through the training it was noticeable that they were generally given a lower rating, but due to the small numbers no real conclusion can be drawn.

\section{Results: Skills developed through being a coach}

Overwhelmingly the results showed that students valued the relationship with their peer coach and that the process of developing the relationship itself has an impact on practice. Tables 1 and 2 show that student teachers thought their relationships were both positive and useful for developing both aspects of their teaching and the written elements of the course. Peer coaching provided a forum in which student teachers could listen and discuss their practice in a different context - through doing this they not only developed their listening skills but also skills of giving advice, communication, sharing ideas and reflecting on both their classroom practice and relationships within their schools. Through the process of coaching the students were able to appreciate the benefits of teamwork. All of these personal skills are important criteria to successfully complete the PGCE course [31]. They also develop classroom confidence, an attribute required to be an effective teacher, which in turn will help them to be successful practitioners.

From all the responses it was clear that the students were positive about being given the opportunity to discuss their teaching practice. They also found the process very reflective and stress relieving. Below are some examples from the interim questionnaire about how useful the students found the process;

"It was good having someone to bounce ideas off"

"Good to get another person's perspective"

"Able to support each other when morale is down"

"My coach helped me to sort out my files and paperwork"

All of the above indicate the peer coach was someone they felt supported by and indicate a real need for students to have access to a coach during what is a very demanding and stressful time for them. These quotes indicate that the students were being involved in aspects of confidence such as being more persistent [21] and open to ideas [20]. Coaching can help students to empathise with different points of view, which can help them to reflect upon what other people say about their own teaching.

One of the emerging themes from the responses of the end of practice questionnaires was that through peer coaching, students had improved how they would interact and respond to others in a professional capacity - this is evidence, we believe, of improved confidence and an evolving teacher identity. Below are two further examples;

"Seeing how upset my friend was about the underlying attitude of his mentor, it was clear that the mentor, whilst not doing anything directly insulting, was causing him to be made to feel unappreciated and a burden unnecessarily. 
This mirrors feelings I had in my second placement but together we decided that our progress has been great, and we don't need appreciation from others, as we are going to be effective teachers in ourselves"

"A's mentor was not fulfilling his role as a mentor and, by and large, neither was mine. From this, there was common ground to empathise and encourage one another to stay focused and get as much as possible from SE2"

The first quote, in particular, indicates a developing self-efficacy and an ability to stand up for themselves [20]. In a few cases, as already identified, where the relationships between mentor and student teacher were poor the peer coach played a pivotal role. An impact of working with people who do not value you sufficiently can be a reduced capacity to feel confident. This is a complex attribute but Questionnaire 3 provided evidence that this was happening. The students were asked 'What were the three most successful developments your coachee made' the most regular answer (from one fifth of the responses) was in the area of being confident and assured. Other responses included related factors such as 'being more positive', 'being more balanced so I could be more laidback' and being more 'secure', these also indicate the development of confidence in the students.

More evidence that the students had learnt to respond to others came in Questionnaire 3 where the students reported that they felt that their coach was able to pick up on their difficulties - giving a mean of 6.7 on an 8 point Lickert scale. Similarly, in response to the question 'To what extent did your coach recognise your ability to develop' on an 8 point bi-polar scale ( $8=$ a lot; $1=$ a little) the students mean was 6.4. Being confident in your own practice allows you to begin to feel able to offer advice to others. Through the process of giving advice, one can reflect on one's own practice and this whole process can be a very positive experience.

Another aspect was the development of listening skills and interestingly over half the participants felt that they had improved their listening skills through being a coach. One student commented:

"By listening to problems a person is going through it helps that person and I love doing this ..... no specifics have to be said but I definitely learned to listen more"

This is interesting because as a beginner teacher, students often have to listen to advice and feedback about themselves. Learning from this experience and recognising critical learning moments as opportunities for peers to verbalise their thoughts requires skill and consideration. The responses illustrate that peer coaching is a process. It is more than just a chat or a moan but through the peer coach the students have another level of support that allows them to progress both personally and professionally on the course. Another aspect of developing the ability to interact and respond is being able to reflect on all forms of practice:

"Evaluating situations - I found it important to be able to listen to a full 'story' when $S$ was having difficulty with a technician and I listened to all of the points and came back with a different outlook and explanation and was able to explain it wasn't only her in that situation”

This is a complex answer that indicates that the writer was able to empathise and use reflective analysis. The general level that students felt that their peer coach had helped them be reflective was reported in Questionnaire 3 where the mean response was 6.6 on the 8 point Lickert scale. There was also a significant response about how the process of coaching helped with professional development including planning lessons, being organised with paperwork and improving subject knowledge. Numerous participants revealed occasions where they had jointly planned lessons with peers, a process they found to be beneficial to both their lesson planning, and classroom delivery. Peers would often help each other if stuck on particular things. For example;

"I met up with my peer coach to revise for the QTS skills test this was very helpful as I was able to look at the questions and we found easier routes to answering them, especially arithmetic"

Students who were fortunate enough to be in the same school found that they worked well as a team together;

"Me and $M$ benefited from teamwork a lot. We observed and supported each others lessons on a casual basis. This helped us to reflect on our own practise and help each other out during lessons, especially with challenging classes. Also, it helped us get used to being observed unexpectedly"

\footnotetext{
"At the beginning of SE2 I had a series of 'bad' lessons. Coffered to help me and we looked through my plans together. She thought I wasn't planning thoroughly enough and made some suggestions. I changed how I planned subsequent lessons and it made a really big difference. I really appreciated the help."
} 
"I had a problem with two pupils in one class who were very difficult, when I told my peer coaches about this I was made aware of just how much this problem affected me, and my anger at the situation was causing more friction. By talking to others, it helped me realise this, so I was then able to be much calmer and positive to the students and diffuse problems with them."

These quotes indicate that students were making decisions for themselves, able to stand up to knocks and were motivated despite problems, all aspects of developing confidence [20-22]. The students were asked 'What do you feel have been your achievements?' as an open list. They listed a wide range of factors that covered both aspects of interactions and professional development. Confidence was one of the most common (from about one fifth of students) along with 'being more organised'; 'and successful completion of the course'. Other common ones were 'being able to ask for help when needed' and 'communication skills'; which collectively suggest that character traits for long term continuing professional development and the advancement of professional attributes into their first year of teaching would continue.

\section{Conclusion}

The student's responses, both on questionnaires and from discussion throughout the year, indicate that the participants felt strongly that peer coaching was a success. One of the key themes is how important it is for students to be able to talk to each other about their progress, establish effective working relationships and learn how to improve their practice through these discussions. This supports a social constructivist approach to learning and recognises peer coaching as a process. It encourages a learner driven climate where student teachers identify goals within their school context. Putting an emphasis on the teachers learning validates the learners (in this case teachers) pursuit to improve and develop skills and also build confidence. Concentrating on the skills and not the individuals involved reduced the importance of sustaining a prolonged relationship with just one peer. In fact it was good to see that some of our students had formed peer relationships with PGCE students that were not on the science course, as this showed that they were able to transfer skills to foster effective working relationships with peers in differing contexts. The fact that they proactively sought out individuals with whom they wished to establish a peer coaching relationship with was a real success of this project. It illustrates that the student teachers really did value the support of a peer coach and they also recognised the capacity of a peer coach to identify areas of development, build confidence and ultimately move their classroom practice forward.

\section{References}

[1] Bakers, R.G. and B. Showers. The Effects of a Coaching Strategy on Teachers' Transfer of Training to Classroom Practice: A six month follow-up study. . in American Educational Research Association. 1984. New Orleans, LA.

[2] Russo, A., School-based coaching. 2004, Harvard Education Letter Research Online.

[3] Showers, B. and B. Joyce, The Evolution of Peer Coaching. Educational Leadership, 1996. 53(6): p. 12-16.

[6] Brember, I., M. Brown, and S. Ralph, Genderrelated Causes of Stress in Trainee Teachers on Teaching Practice in the School of Education. International Journal of Research \& Method in Education, 2002. 25(2): p. 175-186.

[7] Foltos, L., Peer Coaching: Changing Classroom Practice and Enhancing Student Achievement. n.d.

[8] Darling, N., et al., Gender, Ethnicity, Development and Risk: Mentoring and the consideration of differences. Journal of Community Psychology, 2006. 34(6): p. 765-779.

[9] Chan, A.W., Mentoring ethnic minority, predoctoral students: an analysis of key mentorpractices. Mentoring \& Tutoring: Partnership in Learning, 2008. 16(3): p. 263-277.

[10] Curee, Mentoring and Coaching CPD Capacity Building Project. n.d., http://www.teachernet.gov.uk/_doc/8864/4.4.10. pdf.

[11] Sekerka, L.E. and J. Chao, Peer Coaching as a Technique To Foster Professional Development in Clinical Ambulatory Settings. Journal of Continuing Education in the Health Professions, 2003. 23(1): p. 30-37.

[12] Sue-Chan, C. and G.P. Latham, The Relative Effectiveness of External, Peer, and Self-Coaches. Applied Psychology: an International Review, 2004. 53(2): p. 260-278.

[13] GTC, Peer Observation (TPLFO2). 2006, Birmingham: General Teaching Council. 
[14] National Union of Teachers, A-Z of Peer Coaching. 2004, National Union of Teachers.

[15] DfEE, Learning and teaching. A strategy for professional development. 2001, London: DfEE 0071/2001.

[16] Rhodes, C. and S. Beneicke, Coaching, Mentoring and Peer-Networking: challenges for the management of teacher professional development in schools. Journal of In-Service Education, 2002. 28(2): p. 297-310.

[17] Cordingley, P., Qualitative study of School Level Strategies for Teachers' CPD. 2007, Centre for the Use of Research \& Evidence in Education (for the GTC): Coventry.

[18] Cordingley, P., et al., The impact of collaborative continuing professional development (CPD) on classroom teaching and learning. Review: How do collaborative and sustained CPD and sustained but not collaborative CPD affect teaching and learning? 2005, EPPI-Centre: London.

[19] EPPI, What do specialists do in CPD programmes for which there is evidence of positive outcomes for pupils and teachers? 2007, EPPICentre , http://eppi.ioe.ac.uk/cms/LinkClick.aspx?fileticket =3tLaxQ4H6PI\%3d\&tabid=2275\&mid=4198\&lan guage=en-US): London.

[20] Cordingley, P., Research and evidenceinformed practice: focusing on practice and practitioners. Cambridge Journal of Education, 2008. 38(1): p. 37-52.

[21] Creasy, J. and F. Paterson, Leading Coaching in Schools. 2005, Nottingham: National College for School Leadership.

[22] Craig, C., Creating Confidence. A handbook for professionals working with young people. 2007, Glasgow: Centre for Confidence and Wellbeing.

[23] White, K.A., Self-Confidence: A Concept Analysis. Nursing Forum, 2009. 44(2): p. 103-114.

[24] Hollenbeck, G. and D. Hall, Self-confidence and Leader Performance. Organizational Dynamics, 2004. 33(3): p. 254-269.

[25] Lokea, A. and F. Chow, Learning partnership - the experience of peer tutoring among nursing students: A qualitative study. International Journal of Nursing Studies, 2007(44): p. 237-244.
[26] Malm, B., Towards a new professionalism: enhancing personal and professional development in teacher education. Journal for Education for Teaching, 2009. 35(1): p. 77-91.

[27] Kleitman, S. and L. Stankov, Self-confidence and metacognitive processes. Learning and Individual Differences, 2007(17): p. 161-173.

[28] Whitmore, J., Coaching for Performance: Growing people, performance and purpose. 2002, London: Nicholas Brealey Publishing.

[29] Matthews, B., Engaging Education. Developing Emotional Literacy, Equity and Coeducation. 2006, Buckingham: McGraw-Hill/Open University Press.

[30] Allard, A.C. and L. Yates, Exploring positive cross-gender peer relations: Year 10 students' perspectives on cross-gender friendships. International Journal of Inclusive Education, 2001. 5(1): p. 33-46.

[31] Matthews, B., Emotional literacy as the engine of equity. Emotional Literacy Update, 2005. 3(21): p. 10-11.

[32] Goldsmiths Science Team, Peer Coaching Guidelines - science. 2008, London: Goldsmiths (PGCE Science).

[33] TDA, Professional Standards for Teachers. 2007, London: Training and Development Agency for Schools. 